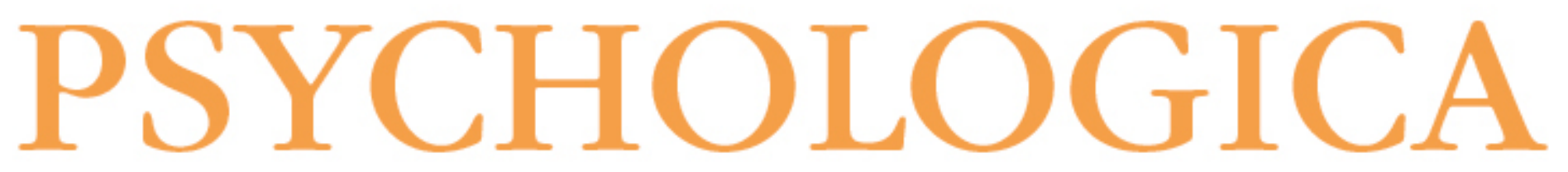

Processos narrativos de mudança em psicoterapia: estudo de um caso de sucesso de terapia construtivista

Autor(es): $\quad$ Ribeiro, António; Gonçalves, Miguel M.; Ribeiro, Eugénia

Publicado por: Imprensa da Universidade de Coimbra

URL

persistente: URI:http://hdl.handle.net/10316.2/5432

DOI: DOI:http://dx.doi.org/10.14195/1647-8606_50_9

Accessed : $\quad$ 26-Apr-2023 09:38:21

A navegação consulta e descarregamento dos títulos inseridos nas Bibliotecas Digitais UC Digitalis, UC Pombalina e UC Impactum, pressupõem a aceitação plena e sem reservas dos Termos e Condições de Uso destas Bibliotecas Digitais, disponíveis em https://digitalis.uc.pt/pt-pt/termos.

Conforme exposto nos referidos Termos e Condições de Uso, o descarregamento de títulos de acesso restrito requer uma licença válida de autorização devendo o utilizador aceder ao(s) documento(s) a partir de um endereço de IP da instituição detentora da supramencionada licença.

Ao utilizador é apenas permitido o descarregamento para uso pessoal, pelo que o emprego do(s) título(s) descarregado(s) para outro fim, designadamente comercial, carece de autorização do respetivo autor ou editor da obra.

Na medida em que todas as obras da UC Digitalis se encontram protegidas pelo Código do Direito de Autor e Direitos Conexos e demais legislação aplicável, toda a cópia, parcial ou total, deste documento, nos casos em que é legalmente admitida, deverá conter ou fazer-se acompanhar por este aviso. 


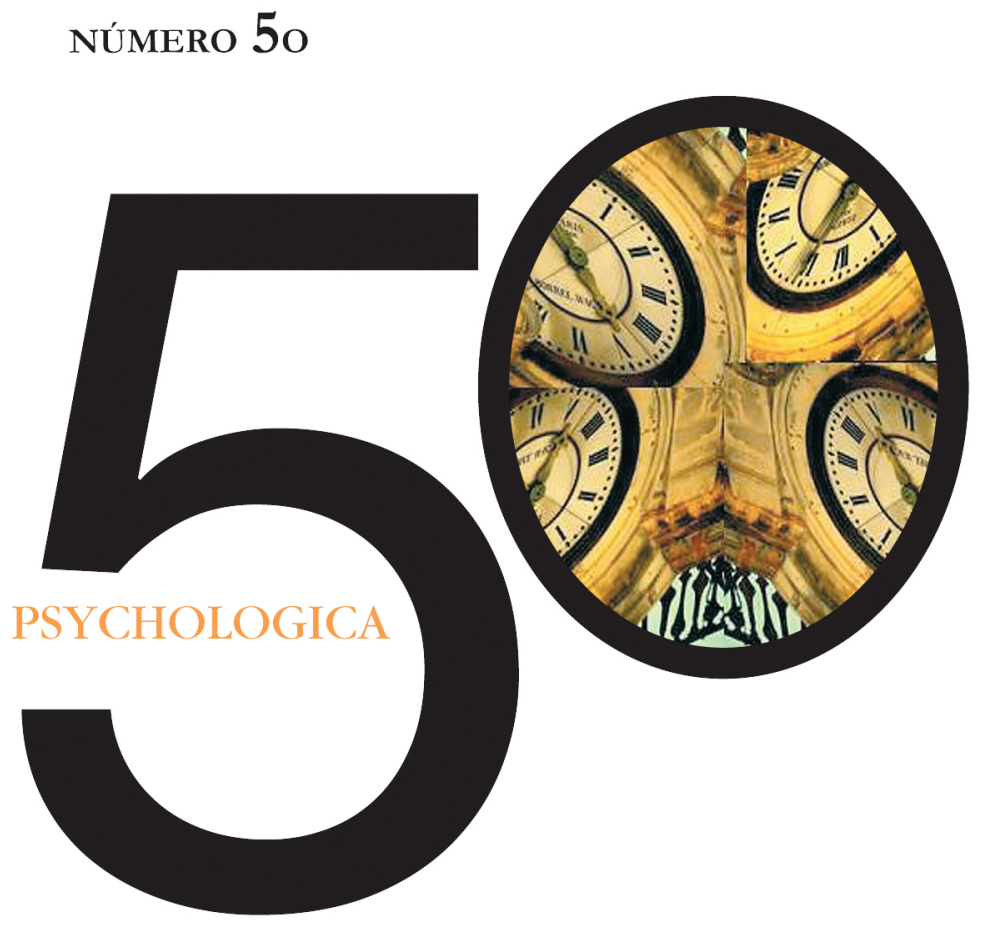

IMPRENSA DA UNIVERSIDADE DE COIMBRA

FACULDADE DE PSICOLOGIA E DE CIÊNCIAS DA EDUCAÇÃO DA UNIVERSIDADE DE COIMBRA 


\title{
Processos narrativos de mudança em psicoterapia: Estudo de um caso de sucesso de terapia construtivista'
}

\author{
António Ribeiro, Miguel M. Gonçalves \& Eugénia Ribeiro²
}

\begin{abstract}
Segundo a terapia narrativa de White, a mudança ocorre a partir da identificação e expansão dos resultados únicos, entendidos como excepções à narrativa problemática. O Sistema de Codificação de Momentos de Inovação (SCMI) foi desenvolvido para identificar estas novidades narrativas - que denominamos momentos de inovação (Mls) - nas sessões de psicoterapia. Este sistema permite identificar 5 tipos de Mls: acção, reflexão, protesto, reconceptualização e desempenho da mudança. Pretendemos compreender como é que os diferentes tipos de MIs emergem ao longo do processo terapêutico. Deste modo, apresentamos a análise do processo de mudança de um caso de sucesso de terapia construtivista, a partir do SCMI. A reconceptualização emerge na fase intermédia do processo e evolui progressivamente até ao final. A reflexão está presente ao longo do processo, sendo bastante elevada nas sessões iniciais e intermédias e decrescendo nas sessões finais. Os MIs de desempenho da mudança, acção e protesto estão quase ausentes.
\end{abstract}

PALAVRAS-CHAVE: Momentos de Inovação; Mudança narrativa; Terapia Construtivista.

\section{Introdução}

\subsection{A metáfora narrativa em psicoterapia: Momentos de inovação e mudança}

Desde os anos 80, vários autores têm advogado que a forma predominante pela qual os seres humanos dão sentido e unidade às suas vidas é a narrativa (Bruner, 1986; McAdams, 1993; Polkinghorne, 1988; Sarbin, 1986). Assim, de acordo com a metáfora narrativa em psicoterapia, o processo de mudança ocorre a par da

\footnotetext{
1 A realização deste estudo foi apoiada pela Fundação para a Ciência e Tecnologia (FCT), através da bolsa PTDC/PSI/72846/2006 (“Mudança Narrativa em Psicoterapia”). A correspondência relativa a este artigo deverá ser enviada para: Miguel M. Gonçalves, Escola de Psicologia, Universidade do Minho, Campus de Gualtar, 4710-057 Braga, Portugal. E-mail: mgoncalves@iep.uminho.pt.

Telefone: 253 604220/253 604683. Fax: 253 604221.

2 Escola de Psicologia, Universidade do Minho

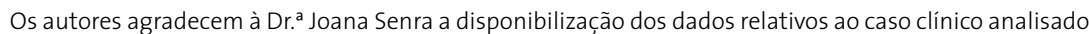


transformação das histórias que os clientes narram acerca das suas vidas, através da reconstrução de significados (Hermans \& Hermans-Jansen, 1995; Omer \& Alon, 1997; Parry \& Doan, 1994; White \& Epston, 1990).

De acordo com a terapia narrativa, esta reconstrução resulta da identificação e da expansão de resultados únicos, isto é, todos os acontecimentos que se situam fora da influência da narrativa problemática que domina a vida da pessoa, seja sob o formato de pensamentos, acções, emoções, projectos ou intenções. A narrativa problemática tende a ser ultrapassada à medida que aumenta a ocorrência de acontecimentos não dominados pelo problema, desde que estes vão sendo dotados de uma textura narrativa. O motivo pelo qual a elaboração de resultados únicos é tão valorizada pela terapia narrativa decorre da assumpção de que aquilo que não é narrado é facilmente esquecido ou desvalorizado. Efectivamente, se estes acontecimentos (pensamentos, acções, desejos e projectos) que ocorrem fora do âmbito da narrativa problemática, não forem elaborados perderão a sua capacidade latente de mudança e serão absorvidos pela narrativa problemática (Freedman \& Combs, 1996; White, 2007; White \& Epston, 1990).

\subsection{A natureza heterogénea dos momentos de inovação}

Ao longo de um conjunto de investigações, Gonçalves, Matos e Santos (2008) desenvolveram o Sistema de Codificação de Momentos de Inovação (SCMI) que pode ser aplicado a contextos terapêuticos e extra-terapêuticos. Este sistema permite a codificação de sessões em vídeo ou transcritas, sendo identificadas momento a momento a ocorrência e duração - que designam de saliência - de resultados únicos. Os autores preferem a designação de momentos de inovação (MIs), dada a natureza ambígua da designação de resultados únicos (cf. Gonçalves, Matos, \& Santos, 2009).

No primeiro estudo em que se utilizou esta metodologia, com mulheres com experiência de maus-tratos acompanhadas em terapia narrativa (Matos, Santos, Gonçalves, \& Martins, 2009), verificou-se que os MIs são experiências heterogéneas, podendo a inovação emergir em cinco tipos diferentes:

1. Os MIs de acção envolvem acções ou comportamentos específicos de desafio ao problema.

2. Os MIs de reflexão implicam a emergência de novas compreensões de carácter cognitivo que não legitimam o problema.

3. Os MIs de protesto correspondem a momentos de dissidência atitudinal, que envolvem confronto face ao problema ou aos aliados do problema.

4. Os MIs de reconceptualização implicam a descrição processual da mudança a partir de um nível metacognitivo. Esta posição permite aceder ao self antigo 
(antes da mudança) e ao self emergente, a partir de uma terceira posição. O/a cliente não só descreve pensamentos e desempenhos fora da lógica do problema, como percebe o processo subjacente.

5. Os MIs de desempenho da mudança envolvem a antecipação ou planeamento de novas experiências, projectos ou actividades a um nível pessoal, profissional e relacional.

\subsection{Modelo genérico de mudança}

Os estudos realizados até ao momento evidenciam que usualmente os MIs estão presentes desde a primeira sessão, em todos os casos de psicoterapia, quer se tratem de processos que envolvem ganhos clínicos significativos ou ganhos mais incipientes (Gonçalves, no prelo). Matos, e colaboradores (2009) constataram que, apesar desta semelhança, habitualmente os casos de sucesso terapêutico se caracterizam por uma maior elaboração de MIs, que se reflecte numa saliência mais elevada. $\mathrm{O}$ padrão típico de desenvolvimento dos Mls, ao longo do processo terapêutico, envolve a emergência de MIs de acção e reflexão na fase inicial da psicoterapia. Por vezes, os MIs de protesto surgem simultaneamente, noutros casos emergem somente depois de um período inicial de acções e reflexões. A meio do processo emerge a reconceptualização e, na fase final da terapia, os MIs de desempenho da mudança. De notar que nos casos em que não se verificam ganhos terapêuticos significativos, a reconceptualização está ausente ou tem uma saliência muito pouco expressiva (cf. Gonçalves, no prelo; para uma análise mais aprofundada).

Assim, parece claro que a presença de MIs não é suficiente para a emergência de novas narrativas (Gonçalves, et al., 2009). Efectivamente, no processo de reautoria, a emergência de novas narrativas implica a articulação dos diferentes tipos de Mls. A partir das amostras que foram analisadas e dos estudos que se encontram em curso, os autores propõem um modelo preliminar de mudança que apresentamos de seguida (ver figura 1).

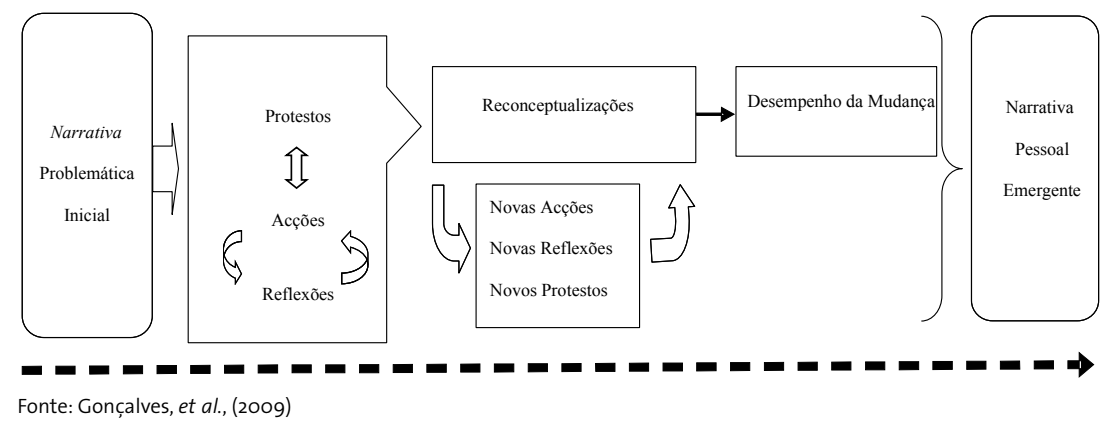

Figura 1: Modelo genérico de mudança 
A mudança em psicoterapia começa com formas elementares de novidade: MIs de acção e reflexão. Por um lado, a pessoa pode começar a reflectir acerca de si, da sua vida ou do problema, de forma divergente da narrativa problemática (MIs de reflexão), agindo em consonância com esta narrativa alternativa, ainda incipiente (Mls de acção). Por outro lado, a pessoa pode começar a agir de forma diferente, atribuindo depois significado a estas acções (MIs de reflexão). Para que estas formas elementares de novidades possam competir com a narrativa problemática, têm que ocorrer alguns ciclos de MIs (reflexão - reflexão e/ou acção - reflexão). O protesto tende a ocorrer concomitantemente ou pouco tempo depois da emergência deste tipo de Mls. Os MIs de protesto envolvem uma atitude mais activa de desafio do problema.

Posteriormente, emerge a reconceptualização que implica uma posição reflexiva face à mudança, a partir de um nível metacognitivo. Esta meta-perspectiva envolve descentração e permite ao indivíduo "olhar de fora" para a mudança, percebendo os processos nela envolvidos. Tal permite ao indivíduo assumir uma posição de autoria: para além de actor, o cliente torna-se autor do seu processo de mudança (utilizando a distinção proposta por Sarbin, 1986).

De acordo com Gonçalves e colaboradores (2009) este tipo de MI funciona como um "campo gravitacional" que atrai e valida as outras formas de inovação, dando uma direcção à mudança. Deste modo, o modelo proposto sugere que depois da reconceptualização podem emergir vários ciclos de acção - reflexão - protesto, que suportam a reconceptualização e são integrados em novas reconceptualizações. Os MIs de desempenho da mudança, em que o indivíduo projecta a nova história para o futuro, põem em marcha um novo processo de validação, que prolonga a reconceptualização no tempo, facilitando pois a consolidação da narrativa emergente.

Deste modo, coloca-se a hipótese de que os vários tipos de MIs assumem, entre si, um poder distinto na emergência da mudança. Assim, os MIs mais elementares - acção, reflexão e protesto - têm potencial para viabilizar a mudança desde que em interacção com outro tipo de Mls - reconceptualização e desempenho da mudança.

\subsection{Modelo genérico de estabilidade: Mutual in-feeding}

Gonçalves e colaboradores (2009; Gonçalves et al., no prelo) chamam a atenção para o facto de determinados MIs - nomeadamente os MIs de acção, reflexão e protesto, na ausência de reconceptualização - poderem tornar-se uma mera oposição ao problema, criando um ciclo vicioso problema - não problema, particularmente notório nos casos de insucesso terapêutico ou em fases iniciais de 
casos de sucesso (Santos, Gonçalves, \& Matos, 2008; Santos \& Gonçalves, 2007). Pelo contrário, devido à sua natureza, a reconceptualização não pode ser a mera negação do problema, já que implica uma síntese entre a narrativa prévia e a emergente.

Valsiner (2002) descreve um processo diálogico que mantém a estabilidade do self, gicas, duas posições distintas alimentam-se reciprocamente, mantendo-se num equilíbrio dinâmico e simbiótico, ou seja, é produzido um ciclo oscilatório entre duas posições, semelhante a uma onda de feedback dinâmico, mas estável na sua ambivalência e incapaz de uma evolução em qualquer dos sentidos (Duarte \& Gonçalves, no prelo).

Do ponto de vista dialógico, existe uma voz problemática e existe outra voz que funciona como sombra da primeira, que permite à pessoa uma libertação temporária do problema, mas facilita o retorno ao mesmo (Gustafson, 1992). O movimento de oscilação entre as duas vozes pode conduzir a uma dicotomia, num movimento sem fim entre o problema e a solução, o que bloqueia o sistema de significados, inviabilizando, assim, a mudança. Deste modo, as narrativas problemáticas podem envolver duas vozes discordantes em equilíbrio dinâmico - uma voz e uma contra-voz (Gonçalves, et al., 2009) (ver figura 2).

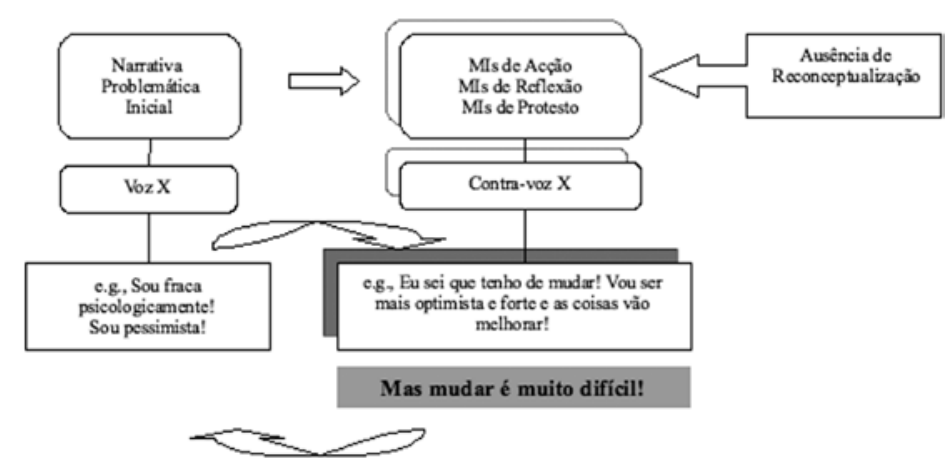

Adaptado de Gonçalves, et al., (2009)

Figura 2: Modelo genérico de estabilidade - Mutual in-feeding 


\subsection{O presente estudo}

Acreditamos que, independentemente do modelo terapêutico utilizado, todos os terapeutas desejam reduzir o poder das narrativas problemáticas nas vidas dos clientes, promovendo e identificando momentos em que estes funcionam de forma diferente. Assim, temos vindo a aplicar o SCMI a diferentes amostras (com problemáticas distintas e em que são utilizados diferentes modelos terapêuticos): terapia narrativa com mulheres vítimas de violência doméstica (Matos, et al., 2009), terapia focada nas emoções e terapia centrada no cliente, numa amostra de depressão (Gonçalves, Mendes, Ribeiro, Angus, \& Greenberg, 2008), bem como mudança espontânea ou não-terapêutica (Meira, Goncalves, Salgado, \& Cunha, no prelo; Cruz \& Gonçalves, 2008). O presente estudo insere-se no esforço de validar a aplicabilidade do SCMI ao estudo da mudança em modelos terapêuticos em que o conceito de resultado único não é central.

Neste estudo, analisamos um caso de sucesso de terapia construtivista centrada na resolução de dilemas implicativos (Fernandes, Senra, \& Feixas, 2009; Senra, Feixas \& Fernandes, 2007). Para além de focarmos os processos narrativos associados à mudança neste caso específico, procurámos aprofundar a compreensão dos mecanismos subjacentes à estabilidade, no sentido de verificar se o processo de mutual in-feeding também está presente num caso de sucesso, a que tipo de MIs está associado e qual o seu desenvolvimento à medida que a terapia evolui.

A análise deste caso assenta na sugestão de Stiles (2007) em relação à redacção de estudos de caso, seguindo uma orientação de construção de teoria ("theory building"). Assim, iremos explorar o processo de mudança à luz do SCMI, analisando posteriormente (na Discussão) os desafios que este caso colocou, as descobertas que permitiu, bem como o modo como informou e enriqueceu o nosso modelo de mudança e de construção de novas narrativas pessoais.

\section{Metodologia}

\subsection{A cliente}

No momento em que teve acompanhamento psicoterapêutico, a Maria era uma estudante universitária de 20 anos que vivia com a sua mãe, sendo a mais velha de três irmãos. O nível socioeconómico da sua família era baixo, usufruindo de uma bolsa de estudo e trabalhando em part-time.

3 O nome da cliente, bem como outros dados que pudessem facilitar a sua identificação foram alterados, no sentido de garantir a confidencialidade. 
A Maria relatava um forte pessimismo que a desgostava bastante. Esse pessimismo tinha efeito no seu rendimento académico, não conseguindo estudar, bem como no relacionamento com o namorado, submetendo-se a situações que Ihe desagradavam e achando que tinha de ser ela a resolver os problemas dele. Isto fazia com que sentisse uma grande discrepância entre aquilo que tinha sido antes da manifestação do problema e a forma como era no momento da terapia. A cliente relatava, ainda, dificuldades ao nivel da sua integração social no contexto universitário, bem como problemas na relação com o pai.

\subsection{A terapia e a terapeuta}

A Maria foi integrada num projecto de investigação a decorrer na Universidade do Minho, sendo as sessões guiadas por um manual de intervenção breve e estruturado (Senra, et al., 2007). O processo terapêutico decorreu ao longo de 12 sessões, com uma periodicidade semanal, sempre que possivel. Realizou-se, ainda, uma sessão de follow-up 4 meses depois da finalização.

O manual que guiou a intervenção da Maria assenta nos princípios do construtivismo pessoal e centra-se na resolução de dilemas implicativos, tal como são identificados pela Grelha de Repertório. Estamos na presença de um dilema implicativo quando o problema (ou um aspecto em que o sujeito deseja mudar) está fortemente associado a dimensões positivas da sua construção de si mesmo, isto é, quando encontramos uma forte ligação entre um construto discrepante (o que o sujeito deseja mudar) e um construto congruente (em que o cliente está satisfeito com a sua posição actual). Esta associação significa que a mudança de pólo num construto implica também a mudança no outro. De acordo com Senra e colaboradores (2007, p. 5), o/a cliente "está bloqueado/a entre o desejo de abandono do problema e o de manter as suas implicações positivas (ou evitar implicações negativas do pólo desejado)".

Depois de explicitar o dilema a trabalhar, o terapeuta procura, no contexto de uma relação colaborativa, promover a compreensão do dilema, facilitando a identificação de situações concretas em que este se manifesta e potenciando, progressivamente, a concepção de formas de construção alternativas, em que o dilema não se verifique (Senra et al., 2007).

A terapeuta foi uma estudante de Doutoramento em psicologia clínica com três anos de experiência clínica prévia como psicoterapeuta e com treino no manual para intervenção em dilemas implicativos. De notar que a terapeuta foi supervisionada pela autora do manual durante o acompanhamento do caso. 


\subsection{O investigador}

O investigador responsável pela codificação e análise deste caso foi um estudante de Mestrado, que integra o grupo de investigação que está a estudar o processo de mudança através do SCMI. Duas estudantes de Doutoramento, com treino no SCMI, também participaram nesta investigação ao codificarem, de forma independente, $50 \%$ do caso cada uma.

No sentido de classificar os MIs quanto à presença ou ausência do processo de mutual in-feeding, uma estudante de Mestrado, que integra o grupo de investigação referido, analisou, de forma independente, todos os MIs.

\subsection{Medidas}

\subsubsection{Medidas de resultados terapêuticos}

No sentido de avaliar a magnitude da mudança, foram utilizados os seguintes instrumentos, no contexto do protocolo de avaliação do projecto de investigação em que este caso se insere:

1. O Inventário de Sintomas Psicopatológicos (Brief Symptom Inventory) - B.S.I (Derogatis, 1982; versão portuguesa adaptada por Canavarro, 1999). Este instrumento foi aplicado 4 vezes (nas fases inicial, intermédia e final da terapia, bem como na sessão de follow up), para medir o grau de sintomatologia. Utilizando como medida o Índice Geral de Sintomas (I.G.S), cuja média é .835 (D.P.=.480) para a população geral e 1.430 (D.P.=.705) para a população com perturbação emocional, podemos verificar que a cliente passou de uma condição clínica na avaliação inicial (2.21) para uma condição sem perturbação na avaliação final (.74), assim como no follow- up (.25).

2. O Outcome Questionnaire - OQ-45.2 (Lambert et al., 1996; versão portuguesa adaptada por Machado \& Klein, 2006) foi utilizado para avaliar o progresso da cliente no decurso do processo terapêutico, tendo sido administrado em todas as sessões, incluindo a de follow-up. A cliente apresentava um score total de 99 na primeira sessão e de 50 na última sessão (19, na sessão de follow-up). Na amostra portuguesa não clínica, estudada por Machado e Klein (2006), as mulheres apresentaram um resultado total médio de 54.00 (D.P.=17.88). Tomando como referência estes valores normativos, no primeiro momento de avaliação, a cliente apresentava um nível de sintomas clinicamente significativo (i.e., o total era mais elevado que a soma da média com dois desvios-padrão), enquanto na última sessão (bem como no follow-up) manifestava um nível característico da população não clínica (i.e., o total situava-se ligeiramente abaixo do valor da média para a população normativa). 
A evolução de um resultado típico da população clínica para um resultado típico da população normal em ambos os instrumentos sugere a existência de mudança significativa, de acordo com um dos critérios propostos por Jacobson e Truax (1991).

\subsubsection{Medidas de Processo}

Para estudar o processo de mudança, o caso foi codificado a partir do Manual de Codificação de Momentos de Inovação - Versão 6.2 (Gonçalves et al., 2008). Na secção dos resultados serão disponibilizados exemplos de cada um dos tipos de Mls identificados. O quadro 1 descreve a grelha a partir da qual os MIs foram codificados, incluindo exemplos para cada tipo.

Quadro 1: Tipos de Mls e exemplos

\begin{tabular}{|c|c|}
\hline Tipos de MI & Exemplos \\
\hline $\begin{array}{l}\text { MI Acção } \\
\text { Acções ou comportamentos } \\
\text { específicos de desafio ao } \\
\text { problema. }\end{array}$ & $\begin{array}{l}\text { a. Novos desempenhos face à antecipada ou efectiva re- } \\
\text { instalação de um obstáculo } \\
\text { b. Resolução efectiva de problemas } \\
\text { c. Exploração activa de soluções específicas } \\
\text { d. Restabelecimento de autonomia e auto-controlo } \\
\text { e. Procura de informação sobre o problema }\end{array}$ \\
\hline $\begin{array}{l}\text { MI Reflexão } \\
\text { Excepções de carácter cogni- } \\
\text { tivo ou produtos cognitivos } \\
\text { (ex. pensamentos, intenções, } \\
\text { interrogações, dúvidas) que } \\
\text { indiciam a compreensão de } \\
\text { algo novo e que não legitimam } \\
\text { o problema. }\end{array}$ & $\begin{array}{l}\text { a. Novas formulações sobre o problema e consciência } \\
\text { dos seus efeitos } \\
\text { b. Novas considerações acerca das causas do problema } \\
\text { c. Articulação de dilemas cognitivos e afectivos } \\
\text { d. Reflexão face às prescrições culturais/sociais/religiosos } \\
\text { e. Referência a crenças de auto-valorização } \\
\text { f. Sentimentos de bem-estar } \\
\text { g. Auto-instruções funcionais ou pensamentos adapta- } \\
\text { tivos } \\
\text { h. Reflexão sobre a intenção de combater prescrições do } \\
\text { problema }\end{array}$ \\
\hline $\begin{array}{l}\text { MI Protesto } \\
\text { Momentos de dissidência ati- } \\
\text { tudinal, envolvendo de algum } \\
\text { modo confronto (endereçado } \\
\text { a outrem ou a facetas de si } \\
\text { próprio). Podem envolver com- } \\
\text { portamentos, pensamentos e } \\
\text { sentimentos, projectados ou } \\
\text { concretizados }\end{array}$ & $\begin{array}{l}\text { a. Resistência cognitiva, comportamental e emocional } \\
\text { face à imposição de constrangimentos } \\
\text { b. Manifestações assertivas face a outros } \\
\text { c. Reposicionamento face às prescrições culturais, } \\
\text { sociais, religiosas e educacionais }\end{array}$ \\
\hline $\begin{array}{l}\text { MI Reconceptualização } \\
\text { Descrição processual, a nível } \\
\text { metacognitivo (i.e., não só } \\
\text { surgem pensamentos e/ou } \\
\text { desempenhos fora da lógica do } \\
\text { problema, como emerge tam- } \\
\text { bém o processo subjacente). }\end{array}$ & $\begin{array}{l}\text { a. Redefinição das versões de si } \\
\text { b. Releitura da sua relação com os outros } \\
\text { c. Atribuição de novos significados (reenquadramento) } \\
\text { a problemas prévios } \\
\text { d. Redefinição da versão elaborada acerca dos outros }\end{array}$ \\
\hline
\end{tabular}




\begin{tabular}{l|l}
\hline $\begin{array}{l}\text { MI Desempenho da Mudança } \\
\text { Referências a novas preten- }\end{array}$ & $\begin{array}{l}\text { a. Generalização de ganhos para outras dimensões da } \\
\text { vida projectada no futuro }\end{array}$ \\
$\begin{array}{l}\text { sões, experiências/actividades } \\
\text { ou projectos em curso ou }\end{array}$ & beutilização da experiência problemática para novas \\
antecipados. & situações \\
& c. Reinvestimentos em novos projectos resultantes do \\
& processo de mudança \\
& d. Reinvestimentos relacionais resultantes do processo \\
& de mudança \\
\hline
\end{tabular}

Fonte: Manual de Codificação de Momentos de Inovação 6.2 (Gonçalves, Matos, \& Santos, 2008)

\subsection{Procedimentos}

A codificação processou-se através da visualização em vídeo das sessões. As sessões foram analisadas sequencialmente (sessão 1, 2, 3, 4...), não se passando para a sessão seguinte sem codificar previamente a anterior. Os codificadores registaram o tipo e a saliência de cada $\mathrm{MI}$ - percentagem de tempo ocupado por cada MI na sessão, por referência ao tempo total da sessão.

Subsequentemente, o codificador principal (o primeiro autor deste estudo) e um segundo juiz analisaram todos os MIs, classificando-os quanto à presença ou ausência de marcadores de retorno ao problema (MRPs). Entende-se por retorno ao problema os momentos em que o/a cliente descreve o MI mas retorna logo a seguir à voz dominante/problemática. É frequente o recurso a conectores linguísticos mas, no entanto, só que, ..., que denotam oposição ou negação em relação ao que está a ser descrito. Surgem logo após o Ml ou no decurso da ocorrência do mesmo.

\section{Ilustração Clínica}

Gostava de ser uma pessoa mais alegre [MI de reflexão], mas sinto-me mesmo muito triste [MRP]. Eu acho que mereço ser feliz [MI de reflexão], mas não consigo, sinto-me mesmo muito triste! [MRP]

Não se considera a presença de MRPs quando o/a cliente: reflecte acerca da mudança; revela consciência real das suas fraquezas e limitações no momento, mostrando-se, no entanto, determinada/o em ultrapassá-los; ou revela consciência de eventuais situações problemáticas, que possam acarretar ansiedade ou constituir risco/perigo (J. Gonçalves, Santos, \& M. Gonçalves, 2008).

\subsection{Fidelidade}

A codificação realizou-se com recurso a três juízes com treino no SCMI. Após a primeira análise das sessões, os codificadores procederam a uma discussão inicial acerca da 
sua visão dos problemas apresentados pela cliente. A partir desta definição consensual dos problemas - que preferencialmente se deve manter próxima da linguagem utilizada pelo/a cliente - é que se tornou possivel identificar os MIs. Assim, todos os MIs são codificados em relação a um problema prévio. Com base no auto-relato da cliente, os codificadores identificaram consensualmente os seguintes problemas, definindo o que constitui uma inovação em relação a cada um (ver quadro 2).

Quadro 2: Problemas e Inovações da Maria

\begin{tabular}{|c|c|}
\hline Problemas & Inovações (MIs) \\
\hline $\begin{array}{l}\text { Pessimismo } \\
\text { "Eu hoje em dia, vejo-me como uma pessoa } \\
\text { muito negativista, sempre a pensar no pior } \\
\text { e não confio tanto em mim"(Sessão 2) }\end{array}$ & $\begin{array}{l}\text { - Momentos em que lida com as dificul- } \\
\text { dades de forma mais optimista, confi- } \\
\text { ando na sua capacidade para resolvê-las }\end{array}$ \\
\hline $\begin{array}{l}\text { Dificuldades na relação com o namorado } \\
\text { "Eu tento ajudá-lo porque vejo que ele se } \\
\text { sente atrapalhado, só que, às vezes, sinto-me } \\
\text { culpada com a minha sinceridade. O facto } \\
\text { de ser honesta com ele e lhe dizer estas } \\
\text { coisas sinto que eu não estou a ajudar e } \\
\text { culpo-me, martirizo-me por ser incompreen- } \\
\text { siva, exigente"(Sessão 4) }\end{array}$ & $\begin{array}{l}\text { - Momentos em que se desresponsabiliza } \\
\text { dos problemas pessoais do namorado } \\
\text { - Momentos em que é assertiva com o } \\
\text { namorado }\end{array}$ \\
\hline $\begin{array}{l}\text { Dificuldades na relação com o pai } \\
\text { "A minha mãe vai dar queixa dele, porque } \\
\text { entretanto ele segue-a, tento ajudar a } \\
\text { minha mãe ...eu queria ajudar mais!" (Ses- } \\
\text { são 4) }\end{array}$ & $\begin{array}{l}\text { - Momentos em que consegue distanciar- } \\
\text { se dos problemas dos pais, conseguindo } \\
\text { gerir com sucesso a sua relação de afasta- } \\
\text { mento com o pai }\end{array}$ \\
\hline $\begin{array}{l}\text { Dificuldades ao nível da integração social } \\
\text { "Sinto-me uma pessoa triste sem grande } \\
\text { vontade de socializar...” (Sessão 2) }\end{array}$ & $\begin{array}{l}\text { - Momentos em que procura aproximar-se } \\
\text { dos colegas de turma } \\
\text { - Momentos em que se sente confortável } \\
\text { na relação com os outros } \\
\end{array}$ \\
\hline $\begin{array}{l}\text { Dificuldades ao nível da gestão do estudo } \\
\text { “...no sábado não fiz nada, totalmente nada, } \\
\text { ora estive na Internet a falar com a Rute, ora } \\
\text { veio mais não sei quem, eu queria pousar o } \\
\text { computador para estudar e não conseguia!" } \\
\text { (Sessão 5) }\end{array}$ & $\begin{array}{l}\text { - Momentos em que gere o tempo de } \\
\text { forma eficaz } \\
\text { - Momentos em que controla os estímulos } \\
\text { de forma a eliminar fontes de distracção } \\
\text { - Momentos em que sente bem-estar } \\
\text { enquanto estuda ou está nas aulas } \\
\text { - Momentos em que conquista bons } \\
\text { resultados académicos }\end{array}$ \\
\hline
\end{tabular}

Concluída esta definição dos problemas/inovações, o juiz principal codificou $100 \%$ da amostra (i.e., as 10 sessões disponíveis), enquanto os restantes dois juízes codificaram 50\% das sessões, cada um: um juiz codificou as sessões $2,3,4$, 5 e 6, outro juiz codificou as sessões 7, 8, 9, 10 e 12. Posteriormente, calculou-se a percentagem de acordo inter-juízes para saliência dos Mls identificados - 84.05\% -, bem como o Kappa de Cohen, no que diz respeito aos diferentes tipos de MIs identificados - 0.90 . 
No que se refere à identificação dos MRPs, calculou-se igualmente o Kappa de Cohen - 0.85 -, tendo em conta a forma como cada um dos juízes classificou o MI (presença ou ausência de MRP), bem como a percentagem de acordo em relação à saliência dos momentos em que a cliente retornou ao problema - 0.95\%.

\section{Apresentação e Análise dos resultados}

\subsection{O impacto dos MIs no progresso terapêutico: Análise Time Series}

Como já tivemos oportunidade de explorar, de acordo com White e Epston (1990), a mudança ocorre a partir da identificação e expansão dos resultados únicos. Esta premissa serve de base a este trabalho, pelo que começaremos por analisar a relação entre a saliência dos MIs ao longo do processo e o progresso da cliente (medido pelo OQ-45), no decorrer da terapia (ver gráfico 1). Tratando-se de um único caso e uma vez que a análise exploratória de dados revelou estarem cumpridos os pressupostos para a utilização de estatística paramétrica, optámos por recorrer a uma análise Time Series (Borckardt, et al., 2008).

A análise de Time Series relatada neste estudo foi realizada através de um programa informático - Simulation Modeling Analysis (S.M.A. 8.3.3., Borckardt, 2006) - uma abordagem estatística que assegura o tratamento da influência das auto-correlações entre os dados (já que se trata do mesmo sujeito em diferentes momentos), acautelando erros de tipo I. De notar, ainda, que todos os coeficientes de correlação calculados têm em conta a correcção de Bonferroni.

Esta análise evidenciou a existência de uma correlação negativa, estatisticamente significativa, na Lag +2 ( $r=-.51, p<.05)$ que sugere que um aumento da saliência de MIs, numa dada sessão, influencia a diminuição do total do OQ-45 (i.e., progresso), duas sessões mais tarde.

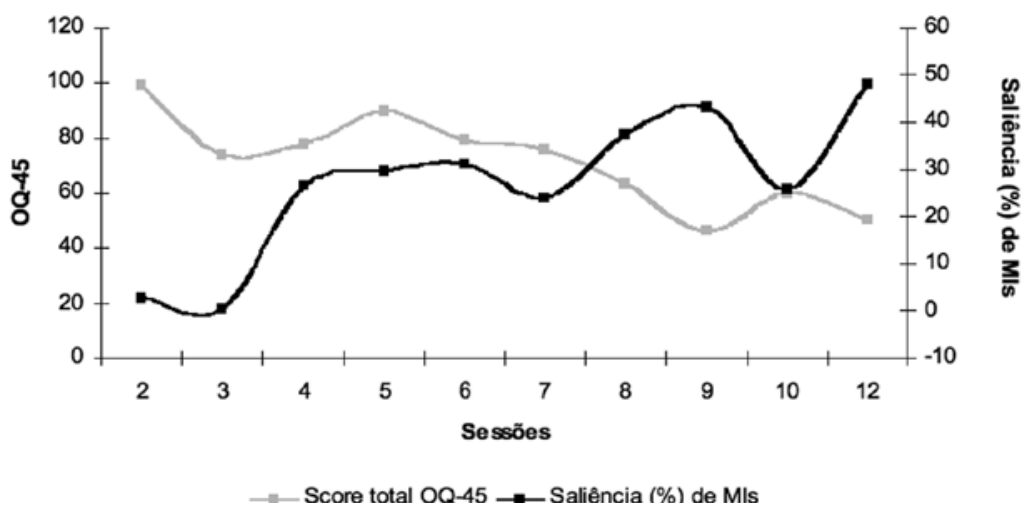

Gráfico 1: Evolução dos resultados terapêuticos e da saliência dos Mls ao longo do processo 


\subsection{Saliência e Diversidade dos MIs}

\subsubsection{Resultados Globais}

Ao longo do processo, $28.23 \%$ do tempo da conversação terapêutica foi ocupado por MIs. O tipo mais saliente foi a reflexão (15.64\%), seguido da reconceptualização (7.73\%). Terapeuta e cliente estiveram envolvidos na elaboração de MIs de acção em $2.29 \%$ do tempo. Relativamente aos restantes 2 tipos - protesto (1.47\%) e desempenho da mudança (1.07\%) - tiveram uma expressão bastante reduzida.

\subsubsection{Análise dos diferentes tipos de $M I$ ao longo do processo terapêutico}

De seguida, analisamos a forma como os diferentes tipos de MIs evoluíram ao longo da psicoterapia. O gráfico 2 representa a evolução da saliência total, bem como da saliência dos MIs de reflexão, de acção e de reconceptualização. A evolução dos MIs de protesto e de desempenho da mudança, não foi representada, na medida em que estes dois tipos de MI apresentaram uma saliência muito baixa.

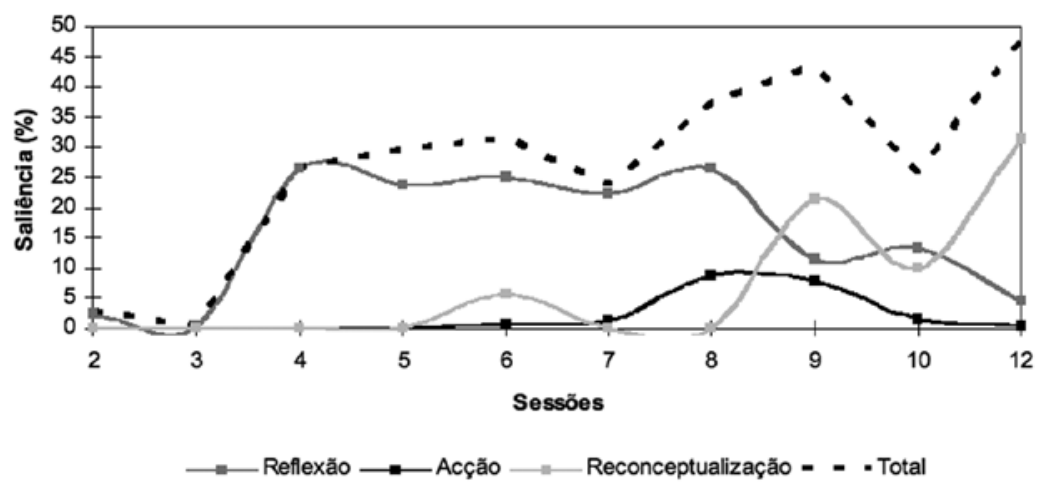

Gráfico 2: Saliência dos MIs ao longo do processo

3.2.2.1. Acção. Este tipo de $M I$ surgiu, pela primeira vez, na sessão 6 , onde teve uma expressão reduzida (0.51\%), e emergiu em todas as sessões subsequentes. De notar que a saliência dos MIs de acção atingiu um pico nas sessões 8 e 9 (8.60\% e $7.70 \%$, respectivamente) e, a seguir, decresceu progressivamente, aproximando-se dos valores das sessões precedentes ( $1.64 \%$ na sessão 10 e $0.41 \%$ na sessão 12 ). 0 conteúdo dos MIs de acção relaciona-se com a implementação de estratégias que permitem à cliente desafiar os diferentes problemas, especialmente as dificuldades na gestão do estudo, no sentido de uma melhor organização e auto-controlo. Num primeiro momento, a cliente relatou sobretudo acções que lhe permitiram ultrapassar o problema no passado - o que White e Epston (1990) designam de resultados únicos históricos (ver ilustração clínica). 
Ilustração clínica (Sessão 7)

Cliente: Eu punha-me a pé cedo... às 8 hzo já estava acordada, para às gh tomaro pequeno-almoço...Às gh já estava a estudar na mesa da cozinha... (MI de acção)

Numa fase posterior, a cliente narrou especialmente momentos em que foi capaz de pôr em prática estratégias - frequentemente recursos que "recuperou" - que Ihe permitiram controlar os efeitos do problema na sua vida (ver ilustração clínica).

Ilustração clínica (Sessão 10)

Cliente: Nestes últimos tempos, tenho optado por estudar no meu quarto... fecho a porta, só fico mesmo com a luz da janela e fico ali num cantinho a estudar, para não me distrair. (MI de acção)

3.2.2.2. Reflexão. A reflexão emergiu desde a segunda sessão (2.31\%) e esteve presente em todas as sessões do processo. A saliência dos MIs de reflexão aumentou dramaticamente da sessão 3 (0.38\%) para a sessão 4 (26.42\%), mantendo-se relativamente estável entre as sessões 4 e 8 . Entre as sessões 8 (26.51\%) e 9 (11.52\%) verificou-se uma primeira quebra da saliência deste tipo de $\mathrm{MI}$, seguida de um segundo movimento descendente, entre as sessões 10 (13.26\%) e 12 (4.47\%). De notar que ambas as quebras coincidiram claramente com picos de reconceptualização.

A elevada saliência da reflexão convidou-nos a uma análise mais fina ao nível do conteúdo dos MIs deste tipo, o que permitiu agrupar as reflexões em dois subtipos:

1. As reflexões de distanciamento em relação ao problema (subtipo I), que incluem novas compreensões acerca das causas e consequências dos problemas; novas formulações dos problemas; intenção de combater o problema; auto-instruções funcionais ou pensamentos adaptativos; alusão a áreas da vida não dominadas pelos problemas; auto-valorização e sentimentos de bem-estar.

2. As reflexões centradas na mudança (subtipo II), que incluem referência a momentos (no passado e no momento actual) em que foi capaz de desafiar o problema; emergência de novas posições face às prescrições do problema; e reflexões acerca do processo de mudança - o cliente elabora sobre qual o processo e as estratégias implementadas para dominar o problema.

Num primeiro momento (sessões 2 a 6), prevaleceram as reflexões de distanciamento em relação ao problema. A cliente foi convidada, pelo questionamento da terapeuta, a repensar os problemas, tendo elaborado novas formulações acerca da sua etiologia (i.e., estratégias do problema para dominar a sua vida) e consequências, o que resultou na possibilidade de distanciamento em relação ao problema (ver ilustração clínica). 


\section{Ilustração clínica (Sessão 5)}

Terapeuta: A descrença nas coisas o que é que faz?

Cliente: Desemboca, ainda mais, em descrenças, em falta de vontade, em desânimo, em falta de confiança, medo de falhar mais uma vez, é um bocado isso que eu penso "vou falhar", e já vou com o pé atrás. Às vezes, penso que já estou predestinada àquilo, não tem lógica porque nunca fui uma falhada, acho eu, pelo menos até à data e também não me considero, sinto-me um bocado em baixo mas vou tendo cada dia um bocado de força que me permite fazer as coisas, também não fico em casa parada, vou fazendo, vou andando... (MI de reflexão - subtipo I)

Pelo contrário, nas sessões que se seguiram (i.e., a partir da sessão 7), as reflexões centraram-se maioritariamente na mudança. De facto, nesta fase da terapia, a cliente reflectiu predominantemente acerca do processo terapêutico e de mudança (ver ilustração clínica).

Ilustração clínica (Sessão 10)

Terapeuta: ...não baixou os braços, está a ser optimista e está a agir com disposição para alcançar os objectivos...

Cliente: $\operatorname{Sim}, \operatorname{sim} \ldots$

Terapeuta: E como é que isso a faz sentir?

Cliente: De certa forma, faz-me sentir bem, porque eu vejo que afinal posso conseguir, que está a dar resultado, que estou a conseguir sair [do problema]... (MI de reflexão - subtipo II)

3.2.2.3. Protesto. A saliência do protesto apresentou um padrão instável. Este tipo de $\mathrm{Ml}$ esteve presente nas sessões 2 e 3 (0.39\% e 0.03\%, respectivamente), tendo desaparecido na sessão 4 . O primeiro pico de protesto aconteceu na sessão 5 (5.53\%) e foi seguido de um decréscimo acentuado (0.34\% na sessão 6). Entre as sessões 6 e 10 a saliência do protesto oscilou entre o\% (na sessão 9) e $2.22 \%$ (na sessão 8). O segundo pico destes Mls ocorreu na última sessão (5.09\%).

Não obstante a reduzida expressão do protesto ao longo do processo, optámos igualmente por explorar este tipo de $\mathrm{MI}$ com mais detalhe, na medida em que num estudo de caso realizado por Gonçalves, Mendes e colaboradores (2008), os MIs de protesto se revelaram essenciais no processo de mudança e mostraram necessitar de uma categorização mais fina. Os autores identificaram, então, dois subtipos:

1. O protesto associado a uma posição orientada para o problema (subtipo I), que implica uma posição de crítica/confronto face ao problema e a outros (pessoas, instituições) que de algum modo o apoiam. 
2. O protesto patente na emergência de novas posições (subtipo II) que implica posições de assertividade face aos outros e empowerment em relação ao problema.

Esta categorização revelou-se aplicável aos MIs de protesto deste caso. Pudemos observar que, na sessão 5 - o primeiro pico de protesto - todos os MIs de protesto são orientado para o problema (subtipo I). O conteúdo destes MIs refere-se, maioritariamente, a momentos em que a Maria assume uma posição de confronto em relação às assumpções do problema (ver ilustração clínica).

Ilustração clínica (Sessão 5)

Cliente: Eu, hoje em dia, vejo-me como uma pessoa muito negativista, sempre a pensar no pior e não confio tanto em mim...há bocado a Dr. a perguntava-me se eu reconheço o meu valor, às vezes eu acho que não... Mas porque é que eu não hei-de ter valor ?! ( MI de protesto - subtipo I)

Pelo contrário, na última sessão - o segundo pico de protesto - todos os MIs de protesto se referiram à emergência de novas posições (subtipo II). O conteúdo deste segundo subtipo referiu-se essencialmente a momentos em que a Maria abandonou a posição submissa que assumia na relação com o namorado, colocando as suas necessidades em primeiro plano e sendo assertiva, o que resulta num sentimento de empowerment (ver ilustração clínica).

Ilustração clínica (Sessão 12)

Cliente: Bati sem querer com a porta do carro dele e ele [refere-se ao namorado] começou a resmungar (...) e a dizer "ainda no outro dia fizeste o mesmo!" (...) Eu assim: "no outro dia?? Fogo, para ti o tempo é mesmo curto! No outro dia?? A única vez que eu te fiz isso já foi há imenso tempo atrás! E mais te digo: lamento muito que tu tenhas tão boa memória para coisas más e, às vezes, tenhas pouca memória para coisas tão boas que já passámos!" (MI de protesto - subtipo II)

3.2.2.4. Reconceptualização. Este tipo de MI surgiu, pela primeira vez, na sessão 6 (5.57\%) - sessão em que emergiram também as primeiras acções -, tendo reaparecido somente na sessão 9 com uma saliência de $21.33 \%$. Seguiu-se uma descida acentuada (10.03\% na sessão 10), congruente com uma descida geral da saliência dos MIs. Esta quebra foi seguida por um incremento notório: 31.45\% na sessão 12.

Nos MIs de reconceptualização, a Maria narrou, a partir de uma meta-posição, o seu processo de mudança, contrastando o self anterior e o self emergente. Além disso, descreveu o processo subjacente a essa transformação, tendo assumido, assim, a autoria da mudança e da construção da sua nova narrativa pessoal (ver ilustração clínica). 
Ilustração clínica (Sessão 12)

Cliente: Ao olhar agora para trás vejo que houve bastante desenvolvimento [contraste] porque, por exemplo, se eu há algum tempo atrás olhava à minha volta e parecia que não tinha saídas, não é, eu vivia ali um bocado congestionada com o meu pai, com o Lucas, com a escola, com isto e com aquilo, com o trabalho e com tudo [self no passado], agora eu acho que sou capaz de deslindar melhor as coisas e não...e sobretudo eu acho que não me deixo afogar tanto por, por essas questões, eu tento não confundir as questões do meu namoro com as questões da escola, já tenho, tenho conseguido nestes últimos dias, após a última consulta, tenho conseguido [self emergente] (...) Procuro não deixar que os sectores se misturem... e acima de tudo não olhar para a minha vida como se fosse a pior de todas, todos nós temos os nossos problemas, os nossos dilemas não é, e portanto eu tento ver as coisas de forma clara e acima de tudo procuro analisar as situações ...[processo] (MI de Reconceptualização)

3.2.2.5. Desempenho da mudança. Os MIs de desempenho da mudança emergiram apenas na fase final da terapia. A expressão deste tipo de $M I$ nas sessões 9 e 10 foi bastante reduzida ( $2.67 \%$ e $0.11 \%$, respectivamente), contudo na última sessão verificou-se um aumento substancial (6.48\%). Importa salientar que os MIs de desempenho da mudança ocorreram frequentemente no contexto de reconceptualizações ou no seguimento destas.

Neste caso encontrámos, essencialmente, dois tipos de desempenho da mudança: por um lado, novos desempenhos e aplicação de novas competências relacionadas com a gestão do estudo (ver ilustração clínica); por outro lado, o reposicionamento nas relações, nomeadamente com o namorado, com o grupo de pares e com o pai.

Ilustração clínica (Sessão 12)

Cliente: Tem acontecido, do género chegar a casa às dez, dez e meia e ainda ter coragem para pegar num livro, tomar um banhinho, sentar-me na cama, pegar num livro e nem que seja ler 4 ou 5 parágrafos, sublinhar, pôr coisas ao lado até me dar aquele sono de cair para o lado... (MI de desempenho da mudança)

\subsection{Retorno ao problema ao longo do processo.}

O gráfico 3 mostra que, até à sessão 5 , a saliência de MIs seguidos de retorno ao problema se justapôs à saliência de MIs que não foram seguidos de retorno ao problema. A partir da sessão 6 , a saliência dos MIs que não foram seguidos de retorno ao problema foi sempre superior, ainda que nas sessões 8 e 9 a saliência dos MIs seguidos de retorno ao problema tenha sido seja bastante expressiva. 


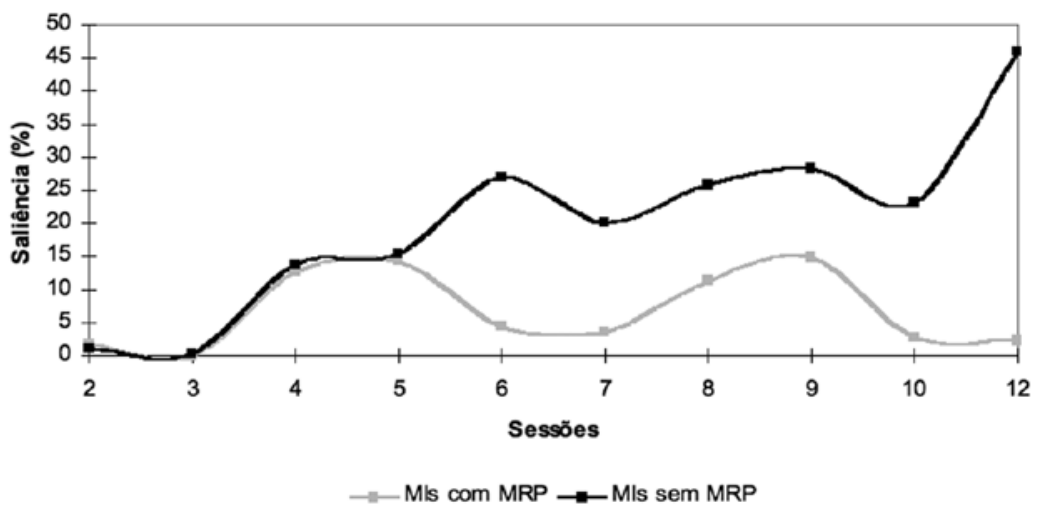

Gráfico 3: Saliência de MIs com e sem MRPs ao longo do processo

\section{Discussão}

Uma das primeiras conclusões que resulta deste estudo refere-se ao facto de o SCMI se mostrar adaptável ao modelo de intervenção utilizado neste caso. Este resultado, integrado no conjunto de dados empíricos (Gonçalves, Mendes, et al., 2008; Matos, et al., 2009) que evidenciam a capacidade de o SCMI se adaptar à análise de casos com intervenções em que o conceito de resultado único não é central, robustece o seu papel como ferramenta de estudo do processo de mudança.

Como tivemos oportunidade de salientar anteriormente, este estudo guiou-se pelos princípios subjacentes ao que Stiles (2007) denomina "theory building case study". De acordo com o autor, as particularidades de cada caso podem potencialmente informar a teoria, não apenas através das semelhanças entre as observações de diferentes casos, mas também a partir da análise das diferenças que a teoria deverá incorporar. Assim, a discussão assentará na exploração das principais similitudes e disparidades deste caso relativamente aos casos anteriormente analisados, focando os ajustes necessários na teoria para que seja capaz de explicar as observações passadas, bem como os dados recentes.

A análise de Time Series revelou a existência de uma correlação negativa estatisticamente significativa entre a saliência dos MIs e o total do OQ-45, o que sugere que um aumento da saliência de MIs, numa dada sessão, influencia a diminuição do total do OQ-45 (i.e., progresso), duas sessões mais tarde. Estes resultados sugerem a existência de uma relação entre saliência de MIs e o progresso do/a cliente (medido pelo total do OQ-45), corroborando a hipótese de que os MIs desempenham um papel de relevo na construção da mudança. 
No que se refere à evolução da saliência dos diferentes tipos de Mls, ao longo do processo, o caso da Maria revela algumas semelhanças com outros casos de sucesso analisados à luz do SCMI. Efectivamente, o papel da reflexão, numa primeira fase da terapia, e a relevância da reconceptualização, numa fase posterior, é compatível com o modelo de mudança proposto na introdução. Todavia, as acções, o protesto e o desempenho da mudança apresentam expressões bastantes reduzidas. Importa, então, analisar estas diferenças.

No que se refere à acção, é relevante sublinhar que este tipo de $\mathrm{Ml}$ é frequentemente elaborado no domínio da significação sob a forma de reflexão e de reconceptualização, isto é, a baixa saliência da acção não significa que estas sejam pouco frequentes ou pouco significativas para o processo de mudança. Apesar de a acção apresentar uma saliência reduzida, ao longo do processo, este tipo de MI parece desempenhar um papel central no processo de mudança, estando envolvido em dois tipos de ciclos que potenciam a reconceptualização. Por um lado, a cliente começou a agir de um modo discrepante da sua auto-narrativa e a explorar esse tipo de acções. A manutenção e a expansão deste tipo de acções divergentes tornaram difícil a persistência de uma auto-narração contraditória com as mesmas. Por outro lado, a cliente começou a aperceber-se de que a sua auto-narração poderia ser diferente, que há até alturas em que se conceptualiza de um modo discrepante. Este processo parece ter criado condições em que esta alternativa narrativa estimulou a emergência de acções consonantes. Estas acções puderam retroagir sobre a auto-narração, tornando-a mais robusta (comporto-me de forma diferente, narro-me de modo diferente) (Gonçalves, 2008).

Assim, o ciclo vicioso auto-narração - acção, que funcionava como um "colete de forças" que mantém a pessoa refém do problema - parece ter dado lugar a um ciclo virtuoso: "quanto mais ajo de modo diferente, menos me narro como um pessimista, mais ajo de um modo diverso" (Gonçalves, 2008). A sucessão de ciclos virtuosos reflexão - acção ou acção - reflexão podem ter contribuído para a consolidação da narrativa emergente, facilitando a emergência de reconceptualizações.

Quanto à baixa saliência de MIs de desempenho da mudança, importa realçar dois aspectos. O primeiro diz respeito ao facto de o modelo genérico de mudança proposto inicialmente ter sido construído a partir de um estudo com terapia narrativa. Efectivamente, os terapeutas narrativos atribuem um papel de relevo ao modo como a imaginação de futuros diferentes pode mudar a forma como a pessoa constrói o presente. O segundo prende-se com o facto de, neste caso, os MIs de desempenho da mudança ocorrerem frequentemente no contexto de reconceptualizações, sendo codificados como tal.

No que se refere ao protesto, comparativamente com os casos de sucesso de terapia narrativa (Matos, et al., 2009) e de terapia focada nas emoções (Gonçal- 
ves, Mendes, et al., 2008), o caso apresentado neste artigo evidencia um nível de protesto bastante baixo. Tal poderá estar relacionado com o facto de os modelos de intervenção supracitados utilizarem técnicas que potenciam este tipo de Mls, nomeadamente a externalização, no caso da terapia narrativa, ou os exercícios de cadeira vazia ou duas cadeiras, no caso da terapia focada nas emoções.

Para além das semelhanças com os casos estudados anteriormente, que permitiram robustecer o nosso modelo genérico de mudança e das diferenças que já analisámos, este caso permitiu enriquecer a nossa grelha de análise ao clarificar a evolução do protesto e da reflexão ao longo da terapia. Efectivamente, estes dois tipos de MIs revelaram necessitar de uma categorização mais fina que espelhasse as suas diferentes manifestações em momentos distintos do processo. A evolução de ambos, ao longo da terapia, parece reflectir o movimento da desconstrução à reconstrução que, segundo White e Epston (1990), caracteriza a evolução dos processos terapêuticos. As reflexões centradas no problema, bem como os protestos centrados na crítica/confronto, estão mais próximos do campo da desconstrução, na medida em que estão relacionados com o questionamento "das verdades não questionadas que sustentam a história problemática” (Gonçalves, 2008, p.20). Por seu turno, as reflexões centradas na mudança, assim como os protestos associados à emergência de posições de assertividade e empowerment, aproximam-se mais do campo da reconstrução, em que a cliente começa a ensaiar novas formas de se relacionar com o problema (Gonçalves, 2008).

A divisão do protesto em dois subtipos (sugerida anteriormente por Gonçalves, Mendes, et al., 2008), bem como a proposta da existência de dois tipos de reflexão, sugerida neste estudo, permitem uma análise mais rica do processo de mudança.

Para além de termos procurado robustecer e refinar o nosso modelo de mudança, preocupámo-nos em explorar qualitativamente a asserção de que a acção, a reflexão e o protesto, na ausência de reconceptualização, podem funcionar como vozes sombra, paralisando o sistema de significados. Efectivamente, vários MIs foram trivializados e desvalorizados, isto é, dominados pelo retorno imediato à voz do problema. Esta voz, usualmente iniciada com uma conjunção adversativa, tornou-se menos saliente ao longo do processo, nomeadamente a partir da sessão 6 , à medida que novas vozes emergiram, contribuindo para a consolidação da narrativa emergente que pôde, assim, constituir-se como uma alternativa à narrativa problemática (Gonçalves, 2008). Este processo parece ter sido facilitado pela reconceptualização que, curiosamente, emerge pela primeira vez na sessão 6. Com efeito, ao contrário dos MIs de acção, reflexão e protesto, que são frequentemente uma mera oposição em relação ao problema (e.g., "Sou pessimista" vs "Quero ser optimista"), potenciando o retorno à narrativa problemática, a reconceptualização parece permitir a assimilação da voz problemática e das novas 
vozes, isto é, a dicotomia problema vs não problema é dialecticamente integrada (Gonçalves, et al., no prelo).

Em suma, os MIs parecem desempenhar um papel de relevo na construção da mudança, a partir da forma como se articulam e evoluem ao longo do processo, o que, de resto, foi corroborado pelos resultados da análise de Time Series. Todavia, os resultados deste estudo, ao sugerirem que determinados MIs podem, efectivamente, alimentar o problema, contrariam a assumpção de White e Epston (1990) de que os resultados únicos são sempre favoráveis à mudança.

\section{Limitações}

As conclusões que resultam deste estudo constituem um importante contributo para o enriquecimento do SCMI. Porém, no futuro, seria fundamental comparar os resultados deste caso com padrões extraídos de uma amostra mais extensa com este modelo de intervenção.

Além do facto de assentar num único caso, uma das maiores limitações deste estudo prende-se com o facto de os codificadores terem conhecimento de que se tratava de um caso de sucesso, o que pode ter enviesado o processo de codificação. No entanto, a elevada percentagem de acordo inter-juízes minora a dimensão deste problema.

Importa ainda salientar que, apesar da análise Time Series ter contribuído para robustecer a nossa análise, este estudo viola um dos pressupostos da sua aplicação: a igualdade dos intervalos de tempo entre as observações. Efectivamente, apesar de as sessões deste caso terem maioritariamente uma periodicidade semanal, algumas aconteceram com um espaçamento maior. Por outro lado, por motivos técnicos, não pudemos codificar as sessões 1 e 11 .

\section{Referências}

Borckardt, J. J., Nash, R. M., Murphy, M., D., Moore, M., Shaw, D., \& O’Neil, P. (2008). Clinical Practice as Natural Laboratory for Psychotherapy Research: A Guide to Case-Based Time-Series Analysis. American Psychologist, 63(2), 77-95.

Bruner, J. (1986). Actual minds, possible worlds. Cambridge, MA: Harvard University Press.

Canavarro, M. C. S. (1999). Inventário de sintomas psicopatológicos - B. S. I. In M. R. Simões, M. M. Gonçalves \& L. S. Almeida (Eds.), Testes e provas psicológicas em Portugal, Vol. II (pp. 95-109). Braga: APPORT/SHO. 
Cruz, G. \& Gonçalves, M. M. (2008). Momentos inovativos e mudança espontânea: Um estudo exploratório. Manuscrito em preparação.

Duarte, F. \& Gonçalves, M. M. (no prelo). A dinâmica dos processos dialógicos no desenvolvimento humano. In K. Moutinho \& P. V. Lyra (Eds.), Novas tendências em psicologia do desenvolvimento: Teoria, pesquisa e intervenção. Brasil.

Fernandes, E., Senra, J., \& Feixas, G., (2009). Terapia construtivista centrada em dilemas implicativos. Braga: Psiquilíbrios.

Freedman, J. \& Combs, G. (1996). Narrative therapy: The social construction of preferred realities. New York: Norton.

Gonçalves, M. M. (2008). Terapia narrativa da re-autoria: O encontro de Bateson, Bruner e Foucault.. Braga: Psiquilíbrios.

Gonçalves, M. M. (no prelo) Momentos de Inovação em Psicoterapia: O que podemos aprender com a psicologia do desenvolvimento? In A. P. Garvey, M. Silva \& M. C. D. P. Lyra (Org.). Microanálise: estudo do processo de mudança. Brasil.

Gonçalves, J., Santos, A., \& Gonçalves, M. M. (2008). Regras para a codificação de marcadores de retorno ao problema. Manuscrito não publicado, Universidade do Minho, Braga.

Gonçalves, M. M., Matos, M., \& Santos, A. (2008). Sistema de Codificação de Momentos de Inovação - versão 6.2. Manuscrito não publicado, Universidade do Minho, Braga.

Gonçalves, M. M. \& Matos, M. \& Santos, A. (2009). Narrative therapies and the nature of "unique outcomes" in the construction of change. Journal of Constructivist Psychology, 22, 1-23.

Gonçalves, M. M., Mendes, I., Ribeiro, A., Angus, L. \& Greenberg, L. (2008). Innovative moments and change in emotional focused therapy: The case of Lisa. Manuscrito em preparação.

Gonçalves, M. M., Santos, A., Matos, M., Salgado, J., Mendes, I., Ribeiro, A., Cunha, C. \& Gonçalves, J. (no prelo). Innovations in psychotherapy: Tracking the narrative construction of change. In J. D. Raskin, S. K. Bridges, \& R. Neimeyer (Eds.), Studies in meaning 4: Constructivist Perspectives on Theory, Practice, and Social Justice. New York: Pace University Press.

Gustafson, J. P. (1992). Self-delight in a harsh world. New York: Norton.

Hermans, H. J. M., \& Hermans-Jansen, E. (1995). Self-narratives: The construction of meaning in psychotherapy. New York: Guilford.

Jacobson, N.S. \& Truax, P. (1991). Clinical significance: A statistical approach to defining meaningful change in psychotherapy research. Journal of Consulting and Clinical Psychology, 59, 12-19.

Meira, L., Gonçalves, M. M., Salgado, J. \& Cunha, C. (2008). Everyday life change: Contribution to the understanding of daily human change. Paper apresentado no 2nd International Conference on Psychology, Atenas, Grécia.

Machado, P.P.P., \& Klein, J. (2006). Outcome Questionraire-45: Portuguese psychometric data with a non-clinical sample. Poster apresentado na $37^{\text {th }}$ Annual Meeting of the Society for Psychotherapy Research. Edinburgh, Scotland.

Matos, M., Santos, A., Gonçalves, M. M., \& Martins, C. (2009). Innovative moments and therapeutic change: Does the elaboration of "unique outcomes" make a difference? Psychotherapy Research, 19, 68-80.

McAdams, D. P. (1993). The stories we live by: Personal myths and the making of the self. New York: William Morrow.

Omer, H., \& Alon, N. (1997). Constructing therapeutic narratives. Northvale, N. J.: Jason Aronson. 
Parry, A., \& Doan, R. D. (1994). Story re-visions. New York: Guiilford Press.

Polkinghorne, D. E. (1988). Narrative knowing and the human sciences. Albany: State University of New York Press.

Santos, A. \& Gonçalves, M. M. (2007). Novelty cycles in psychotherapy - a single case analysis. Poster apresentado na Society for Psychotherapy Research European Meeting, Madeira, Portugal.

Stiles, W. B. (2007). Theory-building case studies of counselling and psychotherapy. Counselling and Psychotherapy Research, 7, 122-127.

Valsiner, J. (2002). Forms of dialogical relations and semiotic autoregulation within the self. Theory and Psychology, 12, 251-265.

White, M. (2007). Maps of narrative practice. New York: Norton.

White, M. \& Epston, D. (1990). Narrative means to therapeutic ends. New York: Norton.

\section{Narrative processes of change in psychotherapy: A study of a good outcome case of constructivist psychotherapy}

According to White's narrative therapy, the identification and amplification of unique outcomes, known as exceptional moments outside the problematic narrative, are crucial processes for change to occur. The Innovative Moments' Coding System (IMCS) was developed in order to classify these novelty moments - which we call innovative moments (i-moments) - in psychotherapy sessions. This system allows tracking the occurrence of 5 types of i-moments: action, reflection, protest, re-conceptualization and performing change. Our central aim is to highlight the way the different types of i-moments emerge along the therapeutic process. Therefore we present an analysis of the change process of a good outcome case of constructivist therapy, using the IMCS. Congruently with previous studies, re-conceptualization develops from the middle of the therapy with clear upward tendency. Reflection remains stable and consistently salient across initial and intermediate phases, decreasing in the final phase. Action, protest and performing change i-moments are rather absent.

KEYWORDS: Innovative Moments; Narrative Change; Constructivist Psychotherapy. 